\title{
Stability Analysis of Mathematical Models of Meningitis Transmission dynamics with the Effects of Vaccination, Campaign, and Treatment
}

\author{
Analisis Kestabilan Model Matematika Dinamika Penyebaran \\ Penyakit Meningitis dengan Pengaruh Vaksinasi, \\ Kampanye, dan Pengobatan \\ Sulma $^{1 *}$, Syamsuddin Toaha $^{2 *}$, Kasbawati $^{3 *}$
}

\begin{abstract}
Meningitis is an infectious disease caused by bacteria, viruses, and protosoa and has the potential to cause an outbreak. Vaccination and campaign are carried out as an effort to prevent the spread of meningitis, treatment reduces the number of deaths caused by the disease and the number of infected people. This study aims to analyze and determine the stability of equilibrium point of the mathematical model of the spread of meningitis using five compartments namely susceptibles, carriers, infected without symptoms, infected with symptoms, and recovered with the effect of vaccination, campaign, and treatment. The results obtained from the analysis of the model that there are two equilibrium points, namely non endemic and endemic equilibrium points. If a certain condition is met then the non endemic equilibrium point will be asymptotically stable. Numerical simulations show that the spread of disease decreases with the influence of vaccination, campaign, and treatment.
\end{abstract}

Keywords: Model of Spread of Meningitis, Equilibrium Point, Eigenvalue.

\begin{abstract}
Abstrak
Penyakit meningitis merupakan penyakit menular yang disebabkan oleh bakteri, virus, dan protosoa serta berpotensi menimbulkan wabah. Vaksinasi dan kampanye dilakukan sebagai upaya mencegah penyebaran penyakit meningitis, pengobatan mengurangi jumlah kematian yang disebabkan oleh penyakit dan jumlah orang yang terinfeksi. Penelitian ini bertujuan untuk menganalisis dan menentukan kestabilan titik keseimbangan dari model matematika penyebaran penyakit meningitis yang mempertimbangkan lima kompartemen yaitu susceptibles, carriers, infected without symptoms, infected with symptoms, dan recovered dengan pengaruh vaksinasi, kampanye, dan pengobatan. Hasil yang diperoleh dari analisis model terdapat dua titik kesetimbangan, yaitu titik kesetimbangan non endemik dan endemik. Jika suatu syarat tertentu dipenuhi maka titik kesetimbangan non endemik akan stabil asimtotik. Simulasi numerik menunjukkan bahwa penyebaran penyakit berkurang dengan adanya pengaruh pemberian vaksinasi, kampanye, dan pengobatan.
\end{abstract}

Kata kunci: Model Penyebaran Penyakit Meningitis, Titik Kesetimbangan, Nilai Eigen.

\section{Pendahuluan}

Penggunaan model matematika sebagai suatu pendekatan dalam upaya memahami penyebaran penyakit telah banyak digunakan dalam berbagai dinamika penyebaran penyakit. Wiraningsih dkk., $[1,2]$ telah menginvestigasi penyebaran penyakit rabies dan penggunaan vaksin serta pengobatan sebagai upaya penanggulangan penyebaran penyakit. Selain itu, dinamika penyebaran penyakit malaria dengan menggunakan varian-varian model SIR juga

* Program Studi Magister Matematika, FMIPA-UNHAS

Email: ${ }^{1}$ sulmahasma@gmail.com, ${ }^{2}$ syamsuddint@gmail.com, ${ }^{3}$ kasbawati@gmail.com 
Sulma, Syamsuddin Toaha, Kasbawati

telah dikaji oleh Beay dkk., [3] dengan mempertimbangkan faktor migrasi dalam modelnya. Sementara Hartati dkk., [4] menggunakan vaksin dan penyemprotan insektisida sebagai upaya mengatasi penyebaran penyakit malaria. Muin dkk., [5] mengkaji pengembangan model SEIR untuk menganalisis penyebaran penyakit hepatitis dengan menggunakan vaksin dan pengobatan kepada kompartemen yang menderita penyakit hepatitis.

Meningitis adalah peradangan pada meninges. Secara umum dapat disebabkan oleh organisme yaitu bakteri dan virus. Hampir semua bakteri yang masuk ke meninges dapat menyebabkan meningitis. Meningitis bakteri umumnya disebabkan oleh tiga bakteri yaitu Neisseria meningitidis, Haemophilus influenzae, dan Streptococcus pneumoniae [6]. Meningitis bakteri hanya ditemukan pada manusia dan ditularkan dari satu orang ke orang lain [7]. Gejala awal dari meningitis hampir mirip dengan flu yaitu demam dan merasa tidak sehat. Gejala spesifik biasanya akan muncul sangat cepat seperti muntah, sakit kepala parah, kejang, gangguan kesadaran, tidak suka cahaya terang, dan leher kaku. Meningitis dapat mengakibatkan keadaan pingsan, koma, dan kematian [8]. Seseorang dapat menampung bakteri Neisseria meningitidis di hidung dan tenggorokan tanpa gejala apapun. Individu rentan mendapatkan bakteri meningitis ketika melakukan kontak dengan orang yang terinfeksi atau pembawa. Penyakit meningitis akan semakin parah jika gejala tidak terdeteksi cukup awal, bahkan dengan perawatan tepat waktu dapat menyebabkan kematian [9].

Fenomena penyebaran penyakit meningitis menarik untuk dikaji melalui pendekatan model matematika. Model matematika dapat membantu memprediksi dan pengendalian penyakit meningitis di masa akan datang. Martínez dkk., [9] mempelajari penyebaran meningitis meningokokus dengan menggunakan model matematika diskrit berdasarkan automata seluler di mana populasi dibagi menjadi lima kelas yaitu susceptible, carriers, asymptomatic infected, infected with symptomps, dan recovered. Pemodelan fenomena epidemik pertama kali diperkenalkan oleh Kermack dan McKendrik pada tahun 1927 [10]. Asamoah dkk., [6] mengkaji dinamika transmisi meningitis dengan tindakan kontrol berupa vaksinasi dan pengobatan yang diselesaikan dengan menggunakan teori kontrol optimal. Hasil penelitian menunjukkan bahwa strategi terbaik mengendalikan meningitis adalah dengan menggabungkan vaksinasi dan intervensi lain seperti pengobatan. Broutin dkk., [11] mempelajari dinamika meningitis meningokokus di sembilan negara di Afrika dengan menggunakan analisis deret waktu dan metode wavelet, hasil studi mereka menunjukkan bahwa kerja sama internasional dalam bidang kesehatan masyarakat sangat diperlukan untuk mengendalikan infeksi ini.

Dalam artikel ini dikembangkan model matematika penyebaran penyakit meningitis yang mempertimbangkan lima kompartemen, yaitu susceptibles, carriers, infected without symptoms, infected with symptoms, dan recovered. Selanjutnya pada model tersebut diberikan vaksinasi, kampanye, dan pengobatan dalam mekanisme perubahan kompartemen dalam model. Analisis dimulai dengan penentuan kewujudan titik kesetimbangan non endemik dan endemik yang dilanjutkan dengan penentuan kestabilannya melalui pendekatan pelinearan model di sekitar titik kesetimbangan. Beberapa simulasi numerik juga diberikan untuk memvisualisasi trayektori dari kompartemen untuk mengkonfirmasi hasil analitik yang diperoleh.

\section{Model Matematika}

Dinamika penyebaran penyakit meningitis biasanya dibagi menjadi empat kompartemen yaitu susceptibles $(S)$, carriers $(C)$, infected $(I)$, dan recovered $(R)[6,12]$. Pada penelitian ini, populasi dibagi menjadi lima kompartemen dengan membedakan kompartemen infected without symptoms $\left(I_{A}\right)$ dan infected with symptoms $\left(I_{S}\right)$, seperti yang diberikan oleh [9]. Diasumsikan bahwa setiap individu yang lahir atau migrasi adalah sehat dan rentan, kemudian masuk ke dalam kompartemen $S$ dengan laju $\pi$. Populasi $S$ yang divaksinasi mendapatkan 
kekebalan sementara dan berpindah ke kompartemen $R$ dengan laju $\sigma u_{1} S$, dan $\beta$ adalah laju interaksi antara populasi rentan dan terinfeksi. Populasi $C$ diasumsikan dapat sembuh secara alami. Diasumsikan kampanye diberikan kepada populasi $C$ untuk meningkatkan kesadaran masyarakat agar melakukan tes rutin terhadap penyakit meningitis, berpindah ke kompartemen $R$ dengan laju $\phi u_{2} C$. Ketika bakteri telah membanjiri pertahanan tubuh maka infeksi dapat menyebar melalui aliran darah ke meninges sehingga populasi pembawa berpindah ke kompartemen $I_{A}$ dengan laju $\alpha$. Gejala dapat muncul dalam waktu 2-10 hari setelah terpapar (biasanya dalam 5 hari) kemudian berpindah ke kompartemen $I_{S}$ dengan laju $\rho$. Diasumsikan bahwa efek kampanye yang diberikan mampu mendorong masyarakat untuk memeriksakan diri ke pusat-pusat kesehatan sehingga resiko untuk terkena meningitis dapat dikurangi sebelum gejala infeksi muncul yang menghasilkan $\phi u_{2} I_{A}$.

Populasi dalam kompartemen $I_{S}$ diasumsikan tidak memiliki pemulihan alami kecuali diberikan perawatan tepat waktu kemudian berpindah ke $R$ dengan laju $\gamma u_{3} I_{S}$ dan diasumsikan meninggal karena penyakit dengan laju $\delta I_{S}$. Dari perspektif epidemiologis populasi dalam kompartemen $R$ tidak mendapatkan kekebalan permanen sehingga kembali menjadi rentan dengan laju $\theta R$. Model matematika dinamika penyebaran penyakit meningitis dengan pengaruh vaksinasi, kampanye, dan pengobatan diberikan oleh persamaan (2.1).

$$
\begin{gathered}
\frac{d S}{d t}=\pi+\theta R-\frac{\beta\left(1-\sigma u_{1}\right) S\left(\eta C+\eta_{1} I_{A}+\eta_{2} I_{S}\right)}{N}-\left(\mu+\sigma u_{1}\right) S \\
\frac{d C}{d t}=\frac{\beta\left(1-\sigma u_{1}\right) S\left(\eta C+\eta_{1} I_{A}+\eta_{2} I_{S}\right)}{N}-\left(\mu+\omega+\alpha+\phi u_{2}\right) C \\
\frac{d I_{A}}{d t}=\alpha C-\left(\mu+\rho+\phi u_{2}\right) I_{A} \\
\frac{d I_{S}}{d t}=\rho I_{A}-\left(\mu+\gamma u_{3}+\delta\right) I_{S} \\
\frac{d R}{d t}=\sigma u_{1} S+\left(\omega+\phi u_{2}\right) C+\phi u_{2} I_{A}+\gamma u_{3} I_{S}-(\mu+\theta) R,
\end{gathered}
$$

dengan total populasi $N=S+C+I_{A}+I_{S}+R$. Diasumsikan bahwa kondisi awal memenuhi $S(0)>0, C(0) \geq 0, I_{A}(0) \geq 0, I_{S}(0) \geq 0$, dan $R \geq 0$ dengan $\frac{d S}{d t}, \frac{d C}{d t}, \frac{d I_{A}}{d t}$, $\frac{d I_{S}}{d t}$, dan $\frac{d R}{d t}$ berturut-turut menyatakan laju perubahan jumlah populasi rentan, pembawa, terinfeksi tanpa gejala, terinfeksi dengan gejala, dan populasi pulih sementara terhadap waktu. Semua parameter dalam persamaan (2.1) diasumsikan positif. Diagram skematik mengenai

\begin{tabular}{|c|c|c|c|c|}
\hline $\begin{array}{l}\text { Variabel/ } \\
\text { Parameter }\end{array}$ & Deskripsi & Nilai & Satuan & Referensi \\
\hline$S$ & Jumlah populasi rentan meningitis & - & Orang & - \\
\hline C & $\begin{array}{l}\text { Jumlah populasi pembawa bakteri } \\
\text { meningitis }\end{array}$ & - & Orang & - \\
\hline$I_{A}$ & $\begin{array}{l}\text { Jumlah populasi terinfeksi tanpa } \\
\text { gejala }\end{array}$ & - & Orang & - \\
\hline$I_{S}$ & $\begin{array}{l}\text { Jumlah populasi terinfeksi dengan } \\
\text { gejala }\end{array}$ & - & Orang & - \\
\hline$R$ & Jumlah populasi pulih sementara & - & Orang & - \\
\hline$\pi$ & Laju kelahiran dan migrasi & $100-$ & Orang/tahun & [6] \\
\hline
\end{tabular}
pembagian kompartemen model dalam persamaan (2.1) dapat dilihat dalam Gambar 2.1 dan keterangan mengenai semua variabel dan parameter model diberikan secara ringkas dalam Tabel 2.1.

Tabel 2.1. Keterangan Variabel dan Parameter Model dalam Persamaan (2.1). 


\begin{tabular}{|c|c|c|c|c|}
\hline & & 100000 & & \\
\hline$\beta$ & Laju interaksi & 0.88 & $1 /$ tahun & [6] \\
\hline$\eta$ & Laju infeksi populasi $C$ & $0.2-0.85$ & $1 /$ tahun & [6] \\
\hline$\eta_{1}$ & Laju infeksi populasi $I_{A}$ & $0.2-0.95$ & $1 /$ tahun & [6] \\
\hline$\eta_{2}$ & Laju infeksi populasi $I_{S}$ & $0.2-0.95$ & $1 /$ tahun & Asumsi \\
\hline$\gamma$ & Efektivitas pengobatan & $0.1-0.9$ & - & Asumsi \\
\hline$\sigma$ & Efektivitas vaksinasi & $0.85-1$ & - & [9] \\
\hline$\phi$ & Efektivitas kampanye meningitis & $0.85-0.95$ & - & Asumsi \\
\hline$\alpha$ & Laju perpindahan dari $C$ ke $I_{A}$ & $0.1-0.52$ & $1 /$ tahun & [6] \\
\hline$\omega$ & Laju pemulihan alami populasi $C$ & $0.06-0.2$ & $1 /$ tahun & [6] \\
\hline$\rho$ & Laju perpindahan dari $I_{A}$ ke $I_{S}$ & $0.2-0.52$ & $1 /$ tahun & Asumsi \\
\hline$\delta$ & $\begin{array}{l}\text { Laju kematian populasi karena } \\
\text { penyakit }\end{array}$ & $0.05-0.5$ & $1 /$ tahun & [6] \\
\hline$\mu$ & Laju kematian alami & 0.02 & $1 /$ tahun & [6] \\
\hline$\theta$ & Laju perpindahan dari $R$ ke $S$ & $0.04-2$ & $1 /$ tahun & [6] \\
\hline$u_{1}$ & $\begin{array}{llll}\begin{array}{l}\text { Proporsi } \\
\text { divaksinasi }\end{array} & \text { populasi } & S & \text { yang }\end{array}$ & $0-1$ & - & - \\
\hline$u_{2}$ & $\begin{array}{l}\text { Proporsi populasi } C \text { dan } I_{A} \text { yang } \\
\text { diberikan kampanye }\end{array}$ & $0-1$ & - & - \\
\hline$u_{3}$ & $\begin{array}{l}\text { Proporsi populasi } I_{S} \text { yang diberikan } \\
\text { pengobatan }\end{array}$ & $0-1$ & - & - \\
\hline
\end{tabular}

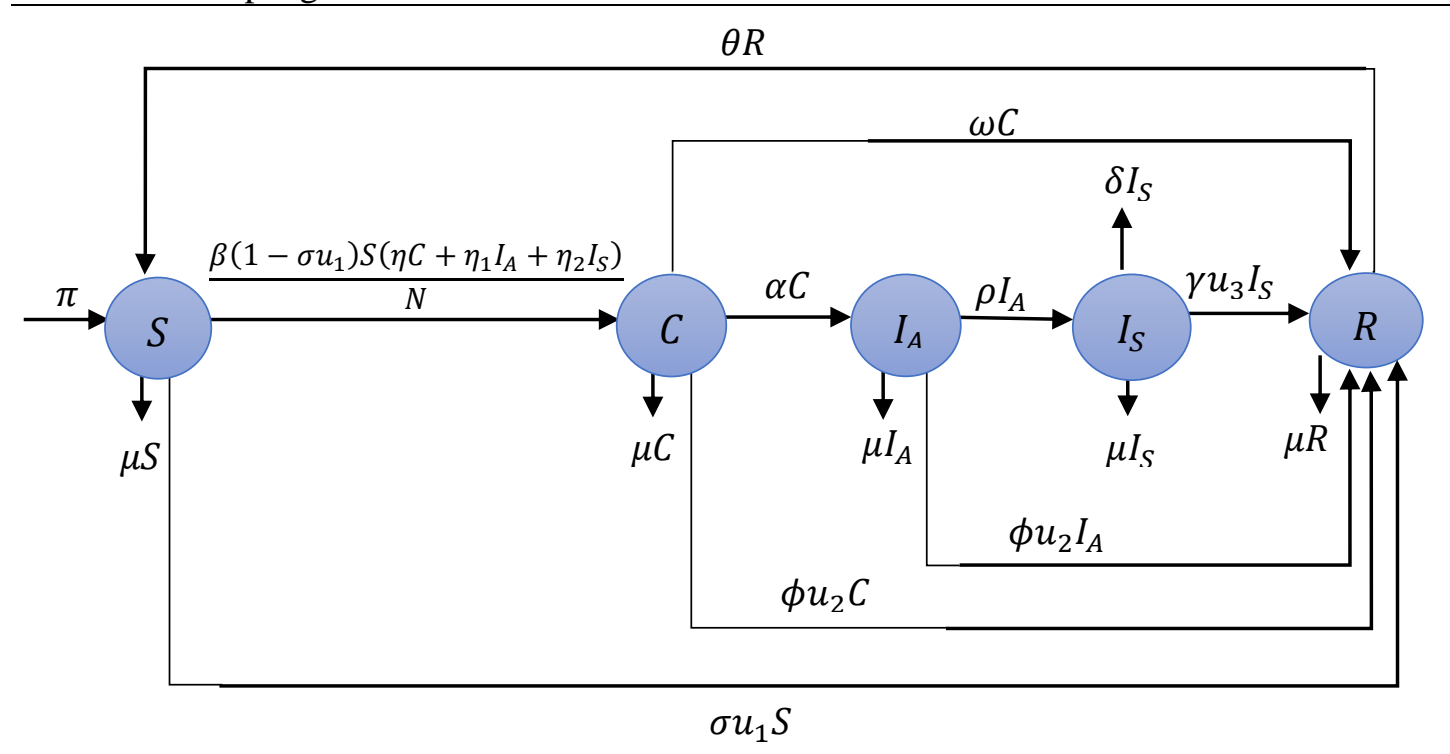

Gambar 2.1. Diagram kompartemen penyebaran penyakit meningitis dengan pemberian vaksinasi $\left(u_{1}\right)$, kampanye $\left(u_{2}\right)$, dan pengobatan $\left(u_{3}\right)$

\section{Hasil dan Pembahasan}

Pada bagian ini, sistem (2.1) akan dianalisis dengan menentukan titik kesetimbangan bebas penyakit dan endemik. Keadaan setimbang dalam model dipenuhi pada saat sistem $\frac{d S}{d t}=\frac{d C}{d t}=\frac{d I_{A}}{d t}=\frac{d I_{S}}{d t}=\frac{d R}{d t}=0$. Titik kesetimbangan bebas penyakit adalah keadaan saat semua kompartemen yang berhubungan dengan penyakit bernilai nol dan dengan itu penyakit tidak menyebar dalam suatu populasi. Dengan memisalkan $\Lambda_{1}=\beta\left(1-\sigma u_{1}\right), \Lambda_{2}=\mu+\sigma u_{1}$, $\Lambda_{3}=\mu+\alpha+\omega+\phi u_{2}, \quad \Lambda_{4}=\mu+\rho+\phi u_{2}, \quad \Lambda_{5}=\mu+\gamma u_{3}+\delta, \quad \Lambda_{6}=\omega+\phi u_{2}, \quad$ dan $\Lambda_{7}=\theta+\mu$, diperoleh titik kesetimbangan bebas penyakit (non endemik), yaitu

$$
\xi_{0}\left(S, C, I_{A}, I_{S}, R\right)=\left(\frac{\pi \Lambda_{7}}{\Lambda_{2} \Lambda_{7}-\sigma u_{1} \theta}, 0,0,0, \frac{\pi \sigma u_{1}}{\Lambda_{2} \Lambda_{7}-\sigma u_{1} \theta}\right) .
$$


Titik kesetimbangan endemik merupakan suatu keadaan saat penyakit meningitis menyebar dalam suatu populasi dan terjadi saat $C>0, I_{A}>0$, dan $I_{S}>0$. Dari sistem (2.1) diperoleh titik kesetimbangan endemik $\xi^{*}\left(S^{*}, C^{*}, I_{A}{ }^{*}, I_{S}{ }^{*}, R^{*}\right)$ dengan

$$
\begin{aligned}
& S^{*}=-\left(\Lambda_{3} \Lambda_{4} \Lambda_{5} \pi\left(\phi u_{2} \Lambda_{5} \alpha+\gamma u_{3} \rho \alpha+\Lambda_{4} \Lambda_{5} \Lambda_{6}+\Lambda_{7} \Lambda_{5} \Lambda_{4}+\Lambda_{7} \rho \alpha+\Lambda_{5} \alpha \Lambda_{7}\right)\right) \\
& /\left(\eta \theta \Lambda_{1} \Lambda_{4}^{2} \Lambda_{5}^{2} \Lambda_{6}-\eta \Lambda_{1} \Lambda_{3} \Lambda_{4}^{2} \Lambda_{5}^{2} \Lambda_{7}+\sigma \theta u_{1} \Lambda_{3} \Lambda_{4}^{2} \Lambda_{5}^{2}-\alpha \Lambda_{2} \Lambda_{3} \Lambda_{4} \Lambda_{5}^{2} \Lambda_{7}\right. \\
& +\gamma \eta \rho \alpha \theta u_{3} \Lambda_{1} \Lambda_{4} \Lambda_{5}+\eta \phi \alpha \theta u_{2} \Lambda_{1} \Lambda_{4} \Lambda_{5}^{2}+\phi \rho \alpha^{2} \theta u_{2} \Lambda_{1} \Lambda_{5} \eta_{2} \\
& +\rho \alpha \sigma \theta u_{1} \Lambda_{3} \Lambda_{4} \Lambda_{5}+\rho \alpha \theta \Lambda_{1} \Lambda_{4} \Lambda_{5} \eta_{2}-\rho \alpha \Lambda_{1} \Lambda_{3} \Lambda_{4} \Lambda_{5} \Lambda_{7} \eta_{2} \\
& +\gamma \rho \alpha^{2} \theta u_{3} \Lambda_{1} \Lambda_{5} \eta_{1}-\gamma \rho \alpha \theta u_{3} \Lambda_{3} \Lambda_{4} \Lambda_{5}-\gamma \rho \alpha u_{3} \Lambda_{2} \Lambda_{3} \Lambda_{4} \Lambda_{5} \\
& +\phi \alpha^{2} \theta u_{2} \Lambda_{1} \Lambda_{5}^{2} \eta_{1}-\phi \alpha \theta u_{2} \Lambda_{3} \Lambda_{4} \Lambda_{5}^{2}-\phi \alpha u_{2} \Lambda_{2} \Lambda_{3} \Lambda_{4} \Lambda_{5}^{2}+\alpha \sigma \theta u_{1} \Lambda_{3} \Lambda_{4} \Lambda_{5}^{2} \\
& +\alpha \theta \Lambda_{1} \Lambda_{4} \Lambda_{5}^{2} \Lambda_{6} \eta_{1}-\alpha \Lambda_{1} \Lambda_{3} \Lambda_{4} \Lambda_{5}^{2} \Lambda_{7} \eta_{1}-\rho \alpha \Lambda_{2} \Lambda_{3} \Lambda_{4} \Lambda_{5} \Lambda_{7}+\gamma \rho^{2} \alpha^{2} \theta u_{3} \Lambda_{1} \eta_{2} \\
& \left.+\sigma u_{1} \Lambda_{3}^{2} \Lambda_{4}^{2} \Lambda_{5}^{2}-\theta \Lambda_{3} \Lambda_{4}^{2} \Lambda_{5}^{2} \Lambda_{6}-\Lambda_{2} \Lambda_{3} \Lambda_{4}^{2} \Lambda_{5}^{2} \Lambda_{6}-\Lambda_{2} \Lambda_{3} \Lambda_{4}^{2} \Lambda_{5}^{2} \Lambda_{7}+\Lambda_{3}^{2} \Lambda_{4}^{2} \Lambda_{5}^{2} \Lambda_{7}\right), \\
& C^{*}=-\left(\Lambda_{4} \Lambda_{5}\left(-\Lambda_{4} \Lambda_{5} \Lambda_{3} u_{1} \sigma+\Lambda_{4} \Lambda_{5} \eta \Lambda_{1} \Lambda_{7}+\Lambda_{1} \eta_{2} \rho \alpha \Lambda_{7}-\Lambda_{4} \Lambda_{5} \Lambda_{3} \Lambda_{7}+\Lambda_{5} \Lambda_{1} \eta_{1} \alpha \Lambda_{7}\right) \pi\right) \\
& /\left(\eta \theta \Lambda_{1} \Lambda_{4}^{2} \Lambda_{5}^{2} \Lambda_{6}-\eta \Lambda_{1} \Lambda_{3} \Lambda_{4}^{2} \Lambda_{5}^{2} \Lambda_{6}-\eta \Lambda_{1} \Lambda_{3} \Lambda_{4}^{2} \Lambda_{5}^{2} \Lambda_{7}+\sigma \theta u_{1} \Lambda_{3} \Lambda_{4}^{2} \Lambda_{5}^{2}\right. \\
& -\alpha \Lambda_{2} \Lambda_{3} \Lambda_{4} \Lambda_{5}^{2} \Lambda_{7}+\gamma \eta \rho \alpha \theta u_{3} \Lambda_{1} \Lambda_{4} \Lambda_{5}+\eta \phi \alpha \theta u_{2} \Lambda_{1} \Lambda_{4} \Lambda_{5}^{2} \\
& +\phi \rho \alpha^{2} \theta u_{2} \Lambda_{5} \Lambda_{1} \eta_{2}+\rho \alpha \sigma \theta u_{1} \Lambda_{3} \Lambda_{4} \Lambda_{5}+\rho \alpha \theta \Lambda_{1} \Lambda_{4} \Lambda_{5} \Lambda_{6} \eta_{2} \\
& -\rho \alpha \Lambda_{1} \Lambda_{4} \Lambda_{5} \Lambda_{3} \Lambda_{7} \eta_{2}+\gamma \rho \alpha^{2} \theta u_{3} \Lambda_{1} \Lambda_{5} \eta_{1}-\gamma \rho \alpha \theta u_{3} \Lambda_{3} \Lambda_{4} \Lambda_{5} \\
& -\gamma \rho \alpha u_{3} \Lambda_{2} \Lambda_{3} \Lambda_{4} \Lambda_{5}+\phi \alpha^{2} \theta u_{2} \Lambda_{1} \Lambda_{5}^{2} \eta_{1}-\phi \alpha \theta u_{2} \Lambda_{3} \Lambda_{4} \Lambda_{5}^{2}-\phi \alpha u_{2} \Lambda_{2} \Lambda_{3} \Lambda_{4} \Lambda_{5}^{2} \\
& +\alpha \sigma \theta u_{1} \Lambda_{3} \Lambda_{4} \Lambda_{5}^{2}+\alpha \theta \Lambda_{1} \Lambda_{4} \Lambda_{5}^{2} \Lambda_{6} \eta_{1}-\alpha \Lambda_{1} \Lambda_{3} \Lambda_{4} \Lambda_{5}^{2} \Lambda_{7} \eta_{1}-\rho \alpha \Lambda_{2} \Lambda_{3} \Lambda_{4} \Lambda_{7} \\
& +\gamma \rho^{2} \alpha^{2} \theta u_{3} \Lambda_{1} \eta_{2}+\sigma u_{1} \Lambda_{3}^{2} \Lambda_{4}^{2} \Lambda_{5}^{2}-\theta \Lambda_{3} \Lambda_{4}^{2} \Lambda_{5}^{2} \Lambda_{6}-\Lambda_{2} \Lambda_{3} \Lambda_{4}^{2} \Lambda_{5}^{2} \Lambda_{6} \\
& \left.-\Lambda_{2} \Lambda_{3} \Lambda_{4}^{2} \Lambda_{5}^{2} \Lambda_{7}+\Lambda_{3}^{2} \Lambda_{4}^{2} \Lambda_{5}^{2} \Lambda_{7}\right) \\
& I_{A}{ }^{*}=-\left(\Lambda_{5}\left(-\Lambda_{4} \Lambda_{5} \Lambda_{3} u_{1} \sigma+\Lambda_{4} \Lambda_{5} \eta \Lambda_{1} \Lambda_{7}+\Lambda_{1} \eta_{2} \rho \alpha \Lambda_{7}-\Lambda_{3} \Lambda_{4} \Lambda_{5} \Lambda_{7}+\Lambda_{5} \Lambda_{1} \eta_{1} \alpha \Lambda_{7}\right) \pi \alpha\right) \\
& /\left(\eta \theta \Lambda_{1} \Lambda_{4}^{2} \Lambda_{5}^{2} \Lambda_{6}-\eta \Lambda_{1} \Lambda_{3} \Lambda_{4}^{2} \Lambda_{5}^{2} \Lambda_{7}+\sigma \theta u_{1} \Lambda_{3} \Lambda_{4}^{2} \Lambda_{5}^{2}-\alpha \Lambda_{2} \Lambda_{3} \Lambda_{4} \Lambda_{5}^{2} \Lambda_{7}\right. \\
& +\gamma \eta \rho \alpha \theta u_{3} \Lambda_{1} \Lambda_{4} \Lambda_{5}+\eta \phi \alpha \theta u_{2} \Lambda_{1} \Lambda_{4} \Lambda_{5}^{2}+\phi \rho \alpha^{2} \theta u_{2} \Lambda_{1} \Lambda_{5} \eta_{2} \\
& +\rho \alpha \sigma \theta u_{1} \Lambda_{4} \Lambda_{5} \Lambda_{3}+\rho \alpha \theta \Lambda_{1} \Lambda_{4} \Lambda_{5} \Lambda_{6} \eta_{2}-\rho \alpha \Lambda_{1} \Lambda_{3} \Lambda_{4} \Lambda_{5} \Lambda_{7} \eta_{2} \\
& +\gamma \rho \alpha^{2} \theta u_{3} \Lambda_{1} \Lambda_{5} \eta_{1}-\gamma \rho \alpha \theta u_{3} \Lambda_{4} \Lambda_{5} \Lambda_{3}-\gamma \rho \alpha u_{3} \Lambda_{2} \Lambda_{3} \Lambda_{4} \Lambda_{5} \\
& +\phi \alpha^{2} \theta u_{2} \Lambda_{1} \Lambda_{5}^{2} \eta_{1}-\phi \alpha \theta u_{2} \Lambda_{3} \Lambda_{4} \Lambda_{5}^{2}-\phi \alpha u_{2} \Lambda_{2} \Lambda_{3} \Lambda_{4} \Lambda_{5}^{2}+\alpha \sigma \theta u_{1} \Lambda_{3} \Lambda_{4} \Lambda_{5}^{2} \\
& +\alpha \theta \Lambda_{1} \Lambda_{4} \Lambda_{5}^{2} \Lambda_{6} \eta_{1}-\alpha \Lambda_{1} \Lambda_{3} \Lambda_{4} \Lambda_{5}^{2} \Lambda_{7} \eta_{1}-\rho \alpha \Lambda_{2} \Lambda_{3} \Lambda_{4} \Lambda_{5} \Lambda_{7}+\gamma \rho^{2} \alpha^{2} \theta u_{3} \Lambda_{1} \eta_{2} \\
& \left.+\sigma u_{1} \Lambda_{3}^{2} \Lambda_{4}^{2} \Lambda_{5}^{2}-\theta \Lambda_{3} \Lambda_{4}^{2} \Lambda_{5}^{2} \Lambda_{6}-\Lambda_{2} \Lambda_{3} \Lambda_{4}^{2} \Lambda_{5}^{2} \Lambda_{6}-\Lambda_{2} \Lambda_{3} \Lambda_{4}^{2} \Lambda_{5}^{2} \Lambda_{7}+\Lambda_{3}^{2} \Lambda_{4}^{2} \Lambda_{5}^{2} \Lambda_{7}\right), \\
& I_{S}{ }^{*}=-\left(\left(-\Lambda_{4} \Lambda_{5} \Lambda_{3} u_{1} \sigma+\Lambda_{4} \Lambda_{5} \eta \Lambda_{1} \Lambda_{7}+\Lambda_{1} \eta_{2} \rho \alpha \Lambda_{7}-\Lambda_{4} \Lambda_{5} \Lambda_{3} \Lambda_{7}+\Lambda_{5} \Lambda_{1} \eta_{1} \alpha \Lambda_{7}\right) \pi \rho \alpha\right) \\
& /\left(\eta \theta \Lambda_{1} \Lambda_{4}^{2} \Lambda_{5}^{2} \Lambda_{6}-\eta \Lambda_{1} \Lambda_{3} \Lambda_{4}^{2} \Lambda_{5}^{2} \Lambda_{7}+\sigma \theta u_{1} \Lambda_{3} \Lambda_{4}^{2} \Lambda_{5}^{2}-\alpha \Lambda_{2} \Lambda_{3} \Lambda_{4} \Lambda_{5}^{2} \Lambda_{7}\right. \\
& +\gamma \eta \rho \alpha \theta u_{3} \Lambda_{1} \Lambda_{4} \Lambda_{5}+\eta \phi \alpha \theta u_{2} \Lambda_{1} \Lambda_{4} \Lambda_{5}^{2}+\phi \rho \alpha^{2} \theta u_{2} \Lambda_{1} \Lambda_{5} \eta_{2} \\
& +\rho \alpha \sigma \theta u_{1} \Lambda_{3} \Lambda_{4} \Lambda_{5}+\rho \alpha \theta \Lambda_{1} \Lambda_{4} \Lambda_{5} \Lambda_{6} \eta_{2}-\rho \alpha \Lambda_{1} \Lambda_{3} \Lambda_{4} \Lambda_{5} \Lambda_{7} \eta_{2} \\
& +\gamma \rho \alpha^{2} \theta u_{3} \Lambda_{1} \Lambda_{5} \eta_{1}-\gamma \rho \alpha \theta u_{3} \Lambda_{3} \Lambda_{4} \Lambda_{5}-\gamma \rho \alpha u_{3} \Lambda_{2} \Lambda_{3} \Lambda_{4} \Lambda_{5} \\
& +\phi \alpha^{2} \theta u_{2} \Lambda_{1} \Lambda_{5}^{2} \eta_{1}-\phi \alpha \theta u_{2} \Lambda_{3} \Lambda_{4} \Lambda_{5}^{2}-\phi \alpha u_{2} \Lambda_{2} \Lambda_{3} \Lambda_{4} \Lambda_{5}^{2}+\alpha \sigma \theta u_{1} \Lambda_{3} \Lambda_{4} \Lambda_{5}^{2} \\
& +\alpha \theta \Lambda_{1} \Lambda_{4} \Lambda_{5}^{2} \Lambda_{6} \eta_{1}-\alpha \Lambda_{1} \Lambda_{3} \Lambda_{4} \Lambda_{5}^{2} \Lambda_{7} \eta_{1}-\rho \alpha \Lambda_{2} \Lambda_{3} \Lambda_{4} \Lambda_{5} \Lambda_{7}+\gamma \rho^{2} \alpha^{2} \theta u_{3} \Lambda_{1} \eta_{2} \\
& \left.+\sigma u_{1} \Lambda_{3}^{2} \Lambda_{4}^{2} \Lambda_{5}^{2}-\theta \Lambda_{3} \Lambda_{4}^{2} \Lambda_{5}^{2} \Lambda_{6}-\Lambda_{2} \Lambda_{3} \Lambda_{4}^{2} \Lambda_{5}^{2} \Lambda_{6}-\Lambda_{2} \Lambda_{3} \Lambda_{4}^{2} \Lambda_{5}^{2} \Lambda_{7}+\Lambda_{3}^{2} \Lambda_{4}^{2} \Lambda_{5}^{2} \Lambda_{7}\right), \\
& R^{*}=-\left(\pi \left(\eta \Lambda_{1} \Lambda_{4}^{2} \Lambda_{5}^{2} \Lambda_{6}+\sigma u_{1} \Lambda_{3} \Lambda_{4}^{2} \Lambda_{5}^{2}+\gamma \eta \rho \alpha u_{3} \Lambda_{1} \Lambda_{4} \Lambda_{5}+\gamma \rho \alpha^{2} u_{3} \Lambda_{1} \Lambda_{5} \eta_{1}\right.\right. \\
& +\eta \phi \alpha u_{2} \Lambda_{1} \Lambda_{4} \Lambda_{5}^{2}+\phi \rho \alpha^{2} u_{2} \Lambda_{1} \Lambda_{5} \eta_{2}-\Lambda_{4} \Lambda_{5} \Lambda_{3} \gamma u_{3} \rho \alpha+\Lambda_{4} \Lambda_{5} \Lambda_{3} u_{1} \sigma \rho \alpha \\
& +\rho \alpha \Lambda_{1} \Lambda_{4} \Lambda_{5} \Lambda_{6} \eta_{2}+\gamma \rho^{2} \alpha^{2} u_{3} \Lambda_{1} \eta_{2}+\phi \alpha^{2} u_{2} \Lambda_{1} \Lambda_{5}^{2} \eta_{1}-\Lambda_{4} \Lambda_{5}^{2} \Lambda_{3} \phi u_{2} \alpha \\
& \left.\left.+\alpha \sigma u_{1} \Lambda_{3} \Lambda_{4} \Lambda_{5}^{2}+\alpha \Lambda_{1} \Lambda_{4} \Lambda_{5}^{2} \Lambda_{6} \eta_{1}-\Lambda_{4}^{2} \Lambda_{5}^{2} \Lambda_{3} \Lambda_{6}\right)\right) /\left(\eta \theta \Lambda_{1} \Lambda_{4}^{2} \Lambda_{5}^{2} \Lambda_{6}\right. \\
& -\eta \Lambda_{1} \Lambda_{3} \Lambda_{4}^{2} \Lambda_{5}^{2} \Lambda_{7}+\sigma \theta u_{1} \Lambda_{3} \Lambda_{4}^{2} \Lambda_{5}^{2}-\alpha \Lambda_{2} \Lambda_{3} \Lambda_{4} \Lambda_{5}^{2} \Lambda_{7}+\gamma \eta \rho \alpha \theta u_{3} \Lambda_{1} \Lambda_{4} \Lambda_{5} \\
& +\eta \phi \alpha \theta u_{2} \Lambda_{1} \Lambda_{4} \Lambda_{5}^{2}+\phi \rho \alpha^{2} \theta u_{2} \Lambda_{1} \Lambda_{5} \eta_{2}+\rho \alpha \sigma \theta u_{1} \Lambda_{3} \Lambda_{4} \Lambda_{5} \\
& +\rho \alpha \theta \Lambda_{1} \Lambda_{4} \Lambda_{5} \Lambda_{6} \eta_{2}-\rho \alpha \Lambda_{1} \Lambda_{3} \Lambda_{4} \Lambda_{5} \Lambda_{7} \eta_{2}+\gamma \rho \alpha^{2} \theta u_{3} \Lambda_{1} \Lambda_{5} \eta_{1} \\
& -\gamma \rho \alpha \theta u_{3} \Lambda_{3} \Lambda_{4} \Lambda_{5}-\gamma \rho \alpha u_{3} \Lambda_{2} \Lambda_{3} \Lambda_{4} \Lambda_{5}+\phi \alpha^{2} \theta u_{2} \Lambda_{1} \Lambda_{5}^{2} \eta_{1}-\phi \alpha \theta u_{2} \Lambda_{3} \Lambda_{4} \Lambda_{5}^{2} \\
& -\phi \alpha u_{2} \Lambda_{2} \Lambda_{3} \Lambda_{4} \Lambda_{5}^{2}+\alpha \sigma \theta u_{1} \Lambda_{3} \Lambda_{4} \Lambda_{5}^{2}+\alpha \theta \Lambda_{1} \Lambda_{4} \Lambda_{5}^{2} \Lambda_{6} \eta_{1}-\alpha \Lambda_{1} \Lambda_{3} \Lambda_{4} \Lambda_{5}^{2} \Lambda_{7} \eta_{1} \\
& -\rho \alpha \Lambda_{2} \Lambda_{3} \Lambda_{4} \Lambda_{5} \Lambda_{7}+\gamma \rho^{2} \alpha^{2} \theta u_{3} \Lambda_{1} \eta_{2}+\sigma u_{1} \Lambda_{3}^{2} \Lambda_{4}^{2} \Lambda_{5}^{2}-\theta \Lambda_{3} \Lambda_{4}^{2} \Lambda_{5}^{2} \Lambda_{6} \\
& \left.-\Lambda_{2} \Lambda_{3} \Lambda_{4}^{2} \Lambda_{5}^{2} \Lambda_{6}-\Lambda_{2} \Lambda_{3} \Lambda_{4}^{2} \Lambda_{5}^{2} \Lambda_{7}+\Lambda_{3}^{2} \Lambda_{4}^{2} \Lambda_{5}^{2} \Lambda_{7}\right) \text {. }
\end{aligned}
$$


Analisis kestabilan titik kesetimbangan untuk sistem (2.1) didekati dengan sistem linear yang menggunakan metode pelinearan dengan menggunakan matriks Jacobi. Dari sistem (2.1) diperoleh matriks Jacobi

$$
J=\left[\begin{array}{lllll}
\frac{\partial f_{1}}{\partial S} & \frac{\partial f_{1}}{\partial C} & \frac{\partial f_{1}}{\partial I_{A}} & \frac{\partial f_{1}}{\partial I_{S}} & \frac{\partial f_{1}}{\partial R} \\
\frac{\partial f_{2}}{\partial S} & \frac{\partial f_{2}}{\partial C} & \frac{\partial f_{2}}{\partial I_{A}} & \frac{\partial f_{2}}{\partial I_{S}} & \frac{\partial f_{2}}{\partial R} \\
\frac{\partial f_{3}}{\partial S} & \frac{\partial f_{3}}{\partial C} & \frac{\partial f_{3}}{\partial I_{A}} & \frac{\partial f_{3}}{\partial I_{S}} & \frac{\partial f_{3}}{\partial R} \\
\frac{\partial f_{4}}{\partial S} & \frac{\partial f_{4}}{\partial C} & \frac{\partial f_{4}}{\partial I_{A}} & \frac{\partial f_{4}}{\partial I_{S}} & \frac{\partial f_{4}}{\partial R} \\
\frac{\partial f_{5}}{\partial S} & \frac{\partial f_{5}}{\partial C} & \frac{\partial f_{5}}{\partial I_{A}} & \frac{\partial f_{5}}{\partial I_{S}} & \frac{\partial f_{5}}{\partial R}
\end{array}\right]
$$

Titik kesetimbangan bebas penyakit disubstitusikan ke dalam matriks Jacobi dan diperoleh

$$
J\left(\xi_{0}\right)=\left[\begin{array}{ccccc}
-\Lambda_{2} & \frac{\Lambda_{1} \pi \Lambda_{7} \eta}{-\pi \Lambda_{7}-\pi \sigma u_{1}} & \frac{\Lambda_{1} \pi \Lambda_{7} \eta_{1}}{-\pi \Lambda_{7}-\pi \sigma u_{1}} & \frac{\Lambda_{1} \pi \Lambda_{7} \eta_{2}}{-\pi \Lambda_{7}-\pi \sigma u_{1}} & \theta \\
0 & \frac{\Lambda_{1} \pi \Lambda_{7} \eta}{\pi \Lambda_{7}+\pi \sigma u_{1}}-\Lambda_{3} & \frac{\Lambda_{1} \pi \Lambda_{7} \eta_{1}}{\pi \Lambda_{7}+\pi \sigma u_{1}} & \frac{\Lambda_{1} \pi \Lambda_{7} \eta_{2}}{\pi \Lambda_{7}+\pi \sigma u_{1}} & 0 \\
0 & \alpha & -\Lambda_{4} & 0 & 0 \\
0 & 0 & \rho & -\Lambda_{5} & 0 \\
\sigma u_{1} & \Lambda_{6} & \phi u_{2} & \gamma u_{3} & -\Lambda_{7}
\end{array}\right] .
$$

Nilai eigen dari matriks Jacobi diperoleh dengan menyelesaikan $\left|J\left(\xi_{0}\right)-\lambda I\right|=0$,

$$
\left|\begin{array}{ccccc}
-\Lambda_{2}-\lambda & \frac{\Lambda_{1} \pi \Lambda_{7} \eta}{-\pi \Lambda_{7}-\pi \sigma u_{1}} & \frac{\Lambda_{1} \pi \Lambda_{7} \eta_{1}}{-\pi \Lambda_{7}-\pi \sigma u_{1}} & \frac{\Lambda_{1} \pi \Lambda_{7} \eta_{2}}{-\pi \Lambda_{7}-\pi \sigma u_{1}} & \theta \\
0 & \frac{\Lambda_{1} \pi \Lambda_{7} \eta}{\pi \Lambda_{7}+\pi \sigma u_{1}}-\Lambda_{3}-\lambda & \frac{\Lambda_{1} \pi \Lambda_{7} \eta_{1}}{\pi \Lambda_{7}+\pi \sigma u_{1}} & \frac{\Lambda_{1} \pi \Lambda_{7} \eta_{2}}{\pi \Lambda_{7}+\pi \sigma u_{1}} & 0 \\
0 & \alpha & -\Lambda_{4}-\lambda & 0 & 0 \\
0 & 0 & \rho & -\Lambda_{5}-\lambda & 0 \\
\sigma u_{1} & \Lambda_{6} & \phi u_{2} & \gamma u_{3} & -\Lambda_{7}-\lambda
\end{array}\right|=0
$$

dan diperoleh polinomial karakteristik dengan

$$
\left(\lambda^{3}+a_{1} \lambda^{2}+a_{2} \lambda+a_{3}\right)\left(\lambda^{2}+\left(\Lambda_{2}+\Lambda_{7}\right) \lambda+\left(\Lambda_{2} \Lambda_{7}-\sigma \theta u_{1}\right)\right)=0,
$$

$$
\begin{gathered}
a_{1}=\frac{\eta \Lambda_{1} \Lambda_{7}-\left(\sigma u_{1}\left(\Lambda_{3}+\Lambda_{4}+\Lambda_{5}\right)+\Lambda_{7}\left(\Lambda_{3}+\Lambda_{4}+\Lambda_{5}\right)\right)}{-\sigma u_{1}-\Lambda_{7}}, \\
a_{2}=\frac{-\left(\Lambda_{7}+\sigma u_{1}\right)\left(\Lambda_{3} \Lambda_{5}+\Lambda_{3} \Lambda_{4}+\Lambda_{4} \Lambda_{5}\right)+\eta \Lambda_{1} \Lambda_{7}\left(\Lambda_{4}+\Lambda_{5}\right)+\alpha \Lambda_{1} \Lambda_{7} \eta_{1}}{-\sigma u_{1}-\Lambda_{7}}, \text { dan } \\
a_{3}=\frac{-\left(\sigma u_{1}+\Lambda_{7}\right)\left(\Lambda_{3} \Lambda_{4} \Lambda_{5}\right)+\Lambda_{5} \Lambda_{1} \Lambda_{7}\left(\Lambda_{4} \eta+\eta_{1} \alpha\right)+\Lambda_{1} \eta_{2} \rho \alpha \Lambda_{7}}{-\sigma u_{1}-\Lambda_{7}} .
\end{gathered}
$$

Dari polinomial karakteristik (3.1) terlebih dahulu akan ditentukan nilai eigen untuk $\left(\lambda^{3}+\right.$ $\left.a_{1} \lambda^{2}+a_{2} \lambda+a_{3}\right)=0$. Berdasarkan kriteria Routh-Hurwitz, lihat [13], semua akar-akar persamaan tersebut mempunyai bagian real yang negatif jika dan hanya jika $D_{1}=a_{1}>$ $0, D_{2}=\left|\begin{array}{cc}a_{1} & a_{3} \\ 1 & a_{2}\end{array}\right|>0, D_{3}=\left|\begin{array}{ccc}a_{1} & a_{3} & 0 \\ 1 & a_{2} & 0 \\ 0 & a_{1} & a_{3}\end{array}\right|>0$. Karena diasumsikan semua parameter bernilai positif maka $D_{1}=a_{1}>0$, jika $\sigma u_{1}\left(\Lambda_{3}+\Lambda_{4}+\Lambda_{5}\right)+\Lambda_{7}\left(\Lambda_{3}+\Lambda_{4}+\Lambda_{5}\right)>\eta \Lambda_{1} \Lambda_{7}$. Syarat $D_{2}>0$ dipenuhi jika dan hanya jika $a_{3}>0$ dan $a_{1} a_{2}>a_{3}$. Jika syarat $D_{2}>0$ maka 
syarat $D_{3}=a_{1} a_{2} a_{3}-a_{3}^{2}>0$ terpenuhi jika dan hanya jika syarat $D_{2}>0$ terpenuhi. Selanjutnya, nilai eigen yang lain dari polinomial karakteristik (3.1) diperoleh dari persamaan $\left(\lambda^{2}+\left(\Lambda_{2}+\Lambda_{7}\right) \lambda+\left(\Lambda_{2} \Lambda_{7}-\sigma \theta u_{1}\right)\right)=0$. Karena diasumsikan semua parameter bernilai positif maka syarat $D_{1}=\Lambda_{2}+\Lambda_{7}>0$, selanjutnya syarat $D_{2}>0$ yaitu $D_{2}=\left|\begin{array}{cc}\left(\Lambda_{2}+\Lambda_{7}\right) & 0 \\ 1 & \left(\Lambda_{2} \Lambda_{7}-\sigma \theta u_{1}\right)\end{array}\right|=\left(\Lambda_{2}+\Lambda_{7}\right)\left(\Lambda_{2} \Lambda_{7}-\sigma \theta u_{1}\right)$, terpenuhi jika $\Lambda_{2} \Lambda_{7}>$ $\sigma \theta u_{1}$. Ketika semua akar-akar polinomial karakteristik (3.1) bernilai negatif atau mempunyai bagian real negatif, maka kondisi ini mengakibatkan titik kesetimbangan bebas penyakit $\xi_{0}$ stabil asimtotik.

Simulasi dinamika model penyebaran penyakit meningitis pada masing-masing populasi dilakukan dengan memvariasikan parameter yang mempengaruhi model tersebut. Simulasi ini menggunakan nilai awal $S(0)=31150, C(0)=1000, I_{A}(0)=300, I_{S}(0)=150$, dan $R(0)=468800$. Nilai awal yang diberikan dalam simulasi ini mengacu kepada beberapa rujukan yang sesuai, yang tentunya boleh jadi belum mewakili fenomena yang sebenarnya. Pada Gambar 3.1 diberikan simulasi sistem dengan nilai parameter $\pi=10000, \beta=0.88$, $\theta=0.04, \mu=0.02, \delta=0.05, u_{1}=0.2, u_{2}=0.3, u_{3}=0.5, \eta=0.7, \eta_{1}=0.8, \eta_{2}=0.85$, $\alpha=0.1, \phi=0.5, \gamma=0.5, \sigma=0.2, \rho=0.2$, dan $\omega=0.2$. Nilai parameter vaksinasi, kampanye, dan pengobatan diberikan relatif yang rendah.

Dengan nilai parameter tersebut diperoleh titik kesetimbangan endemik yaitu $\xi^{*}\left(S^{*}, C^{*}, I_{A}{ }^{*}, I_{S}{ }^{*}, R^{*}\right)=(260884,7184,1941,1214,225742)$ dan seterusnya diperoleh nilai eigen $\lambda_{1}=-0.42+0.11 i, \lambda_{2}=-0.42-0.11 i, \lambda_{3}=-0.02, \lambda_{4}=-0.05+0.03 i$, dan $\lambda_{5}=-0.05-0.03 i$. Karena semua nilai eigen memiliki bagian real yang negatif maka titik kesetimbangan endemik stabil asimtotik, artinya penyakit meningitis akan tetap menyebar dalam populasi.

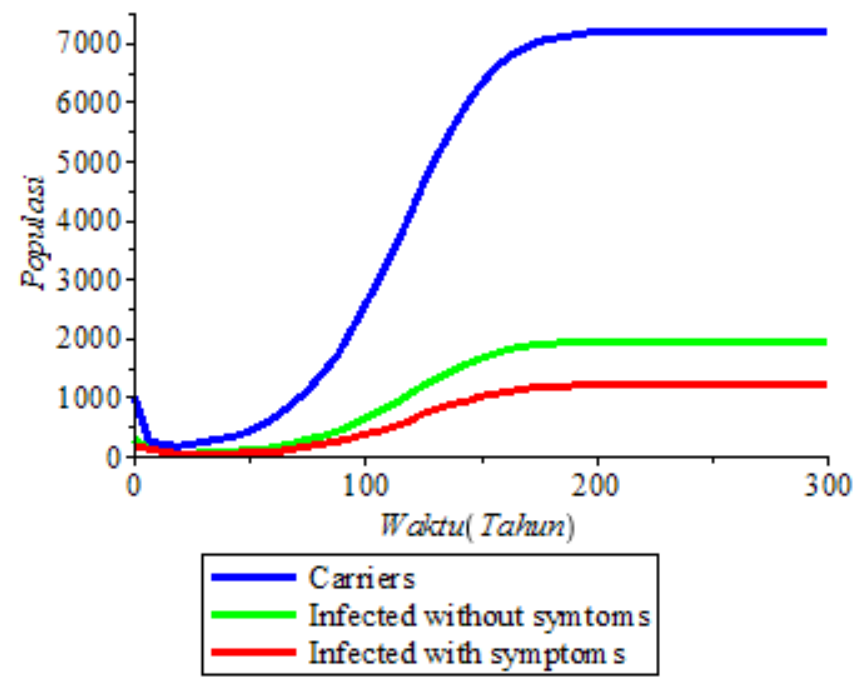

Gambar 3.1. Grafik perubahan populasi Carriers, Infected without symptoms, dan Infected with symptoms terhadap waktu dengan titik kesetimbangan endemik yang stabil

Selanjutnya, diberikan simulasi dengan menaikkan nilai parameter vaksinasi, kampanye, dan pengobatan. Dengan nilai parameter $\pi=10000, \beta=0.88, \theta=0.04, \mu=0.02, \delta=0.05$, $u_{1}=0.3, u_{2}=0.4, u_{3}=0.5, \eta=0.7, \eta_{1}=0.8, \eta_{2}=0.85, \alpha=0.1, \phi=0.5, \gamma=0.5$, $\sigma=0.3, \rho=0.2$, dan $\omega=0.2$ diperoleh titik kesetimbangan non endemik yaitu $\xi_{0}\left(S, C, I_{A}, I_{S}, R\right)=(200000,0,0,0,300000)$ dan nilai eigen $\lambda_{1}=-0.15, \quad \lambda_{2}=-0.02$, $\lambda_{3}=-0.11, \lambda_{4}=-0.45+0.09 i$, dan $\lambda_{5}=-0.45-0.09 i$. Karena semua nilai eigen 
Sulma, Syamsuddin Toaha, Kasbawati

memiliki bagian real yang negatif maka titik kesetimbangan non endemik (bebas penyakit) stabil asimtotik.

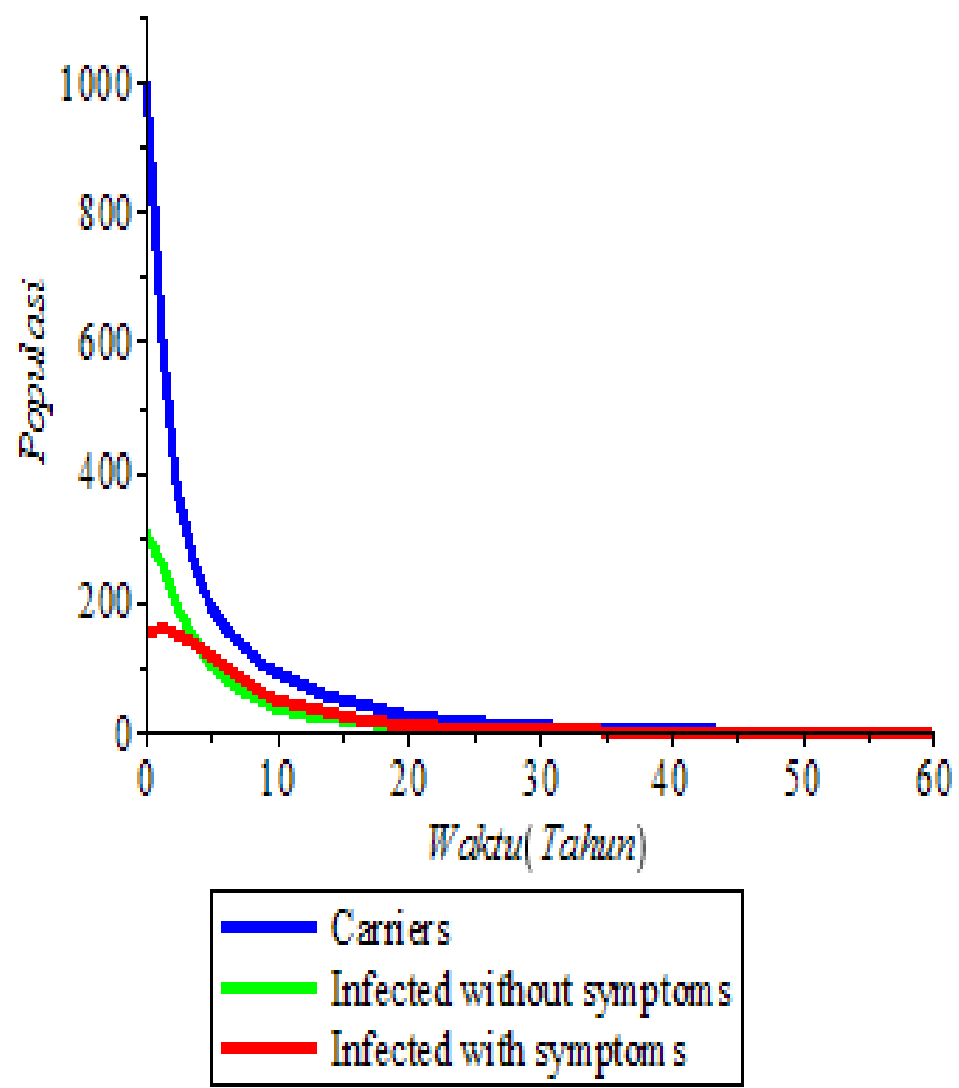

Gambar 3.2. Grafik perubahan populasi Carriers, Infected without symptoms, dan Infected with symptoms terhadap waktu dengan titik kesetimbangan non endemik yang stabil asimtotik

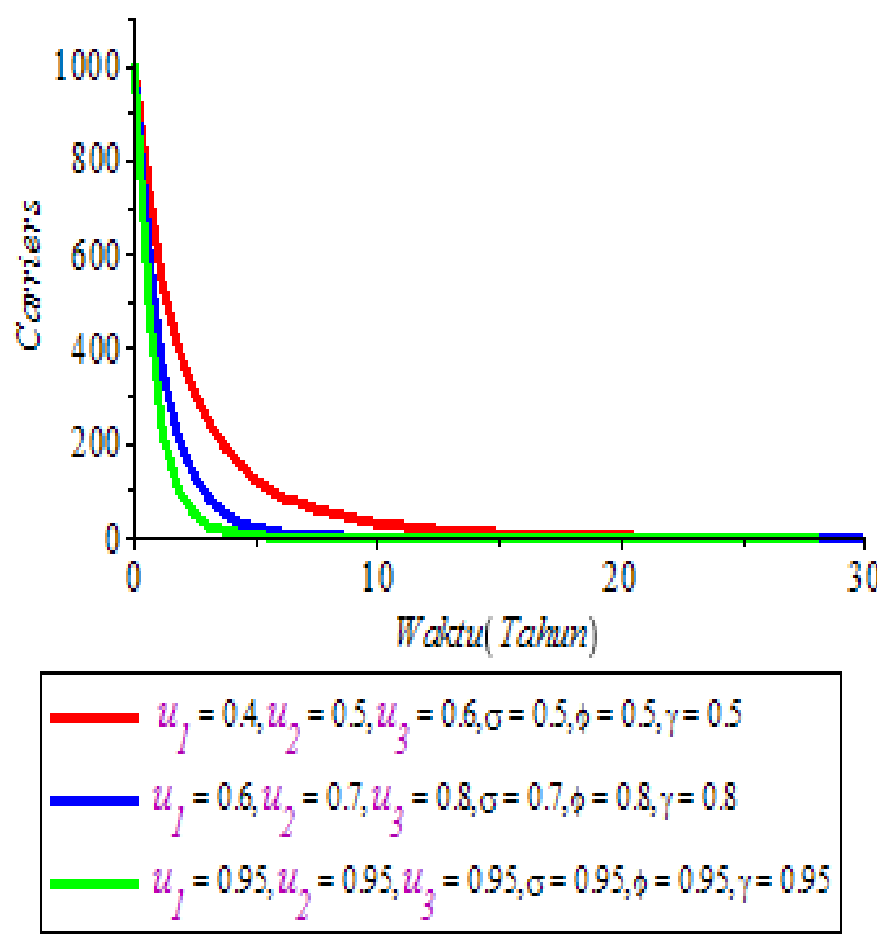


Sulma, Syamsuddin Toaha, Kasbawati

Gambar 3.3. Grafik perubahan populasi Carriers terhadap waktu dengan titik kesetimbangan non endemik yang stabil asimtotik

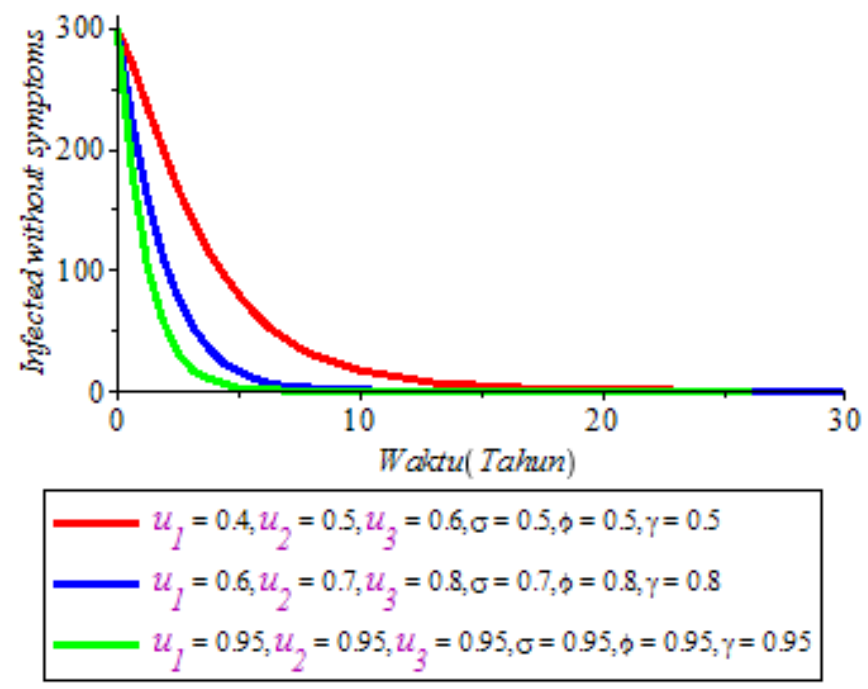

Gambar 3.4. Grafik perubahan populasi Infected without symptoms terhadap waktu dengan titik kesetimbangan non endemik yang stabil asimtotik

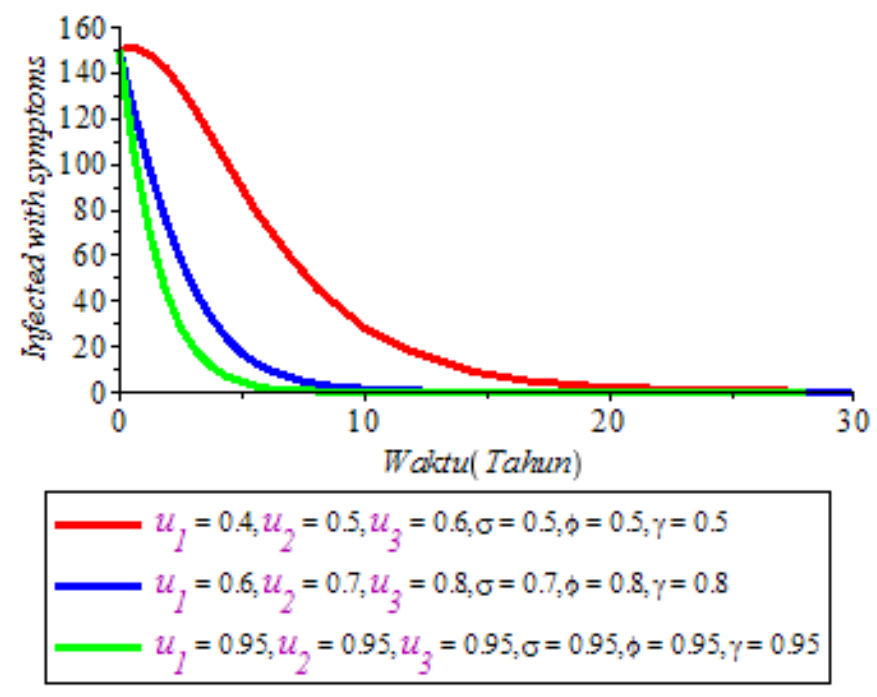

Gambar 3.5. Grafik perubahan populasi Infected with symptoms terhadap waktu dengan titik kesetimbangan non endemik yang stabil asimtotik

Gambar 3.2 menunjukkan bahwa untuk waktu yang semakin bertambah maka jumlah $C, I_{A}$, dan $I_{S}$ akan semakin berkurang dan konvergen ke titik kesetimbangan bebas penyakit. Hanya saja populasi tersebut membutuhkan waktu yang cukup lama untuk konvergen ke titik kesetimbangan bebas penyakit. Gambar 3.3 menunjukkan bahwa jika nilai parameter yang berkaitan dengan vaksinasi, kampanye, dan pengobatan semakin bertambah, maka jumlah populasi Carriers $(C)$ akan semakin cepat berkurang. Hal yang sama juga terlihat pada Gambar 3.4 yaitu populasi Infected without symptoms $\left(I_{A}\right)$ akan konvergen ke titik kesetimbangan bebas penyakit di sekitar $t=5$ tahun. Kemudian, Gambar 3.5 menunjukkan bahwa populasi Infected with symptoms $\left(I_{S}\right)$ akan konvergen ke titik kesetimbangan bebas penyakit di sekitar $t=6$ tahun. Hal tersebut menunjukkan bahwa semakin tinggi proporsi serta efek dari pemberian vaksinasi, kampanye, dan pengobatan maka grafik solusi sistem semakin cepat konvergen ke titik kesetimbangan bebas penyakit. 


\section{Kesimpulan}

Dari hasil analisis dan simulasi yang diberikan dapat disimpulkan bahwa model matematika penyebaran penyakit meningitis dengan pengaruh vaksinasi, kampanye, dan pengobatan diperoleh dua titik kesetimbangan yaitu non endemik $\left(\xi_{0}\right)$ dan endemik $\left(\xi^{*}\right)$. Berdasarkan hasil simulasi diperoleh bahwa ketika pemberian nilai vaksinasi, kampanye, dan pengobatan masih rendah, maka kondisi endemik masih terjadi. Tetapi dengan menaikkan nilai efektivitas vaksinasi $40 \%$, kampanye $50 \%$, dan pengobatan $60 \%$, maka kondisi endemik dapat berubah menjadi kondisi tidak endemik. Akan tetapi, perlakuan tersebut membutuhkan waktu yang lama untuk mencapai kondisi tidak endemik. Kondisi tidak endemik dapat dicapai dalam rentang waktu yang cepat jika efektivitas vaksinasi, kampanye, dan pengobatan sampai 95\%. Hal ini berarti bahwa pemberian vaksinasi, kampanye, dan pengobatan berpengaruh terhadap penurunan penyebaran penyakit meningitis dengan berkurangnya populasi pembawa serta terinfeksi.

\section{Daftar Pustaka}

[1] Wiraningsih, E. D., Aryati, W. L., Toaha, S. \& Lenhart, S. (2010). Optimal control for SEIR rabies model between dogs and human with vaccination effect in dogs. Proceedings of the 6th IMT-GT Conference on Mathematics, Statistics and its Applications (ICMSA2010) Universiti Tunku Abdul Rahman, Kuala Lumpur, Malaysia. Vol. 6. 1161-1175

[2] Wiraningsih, E. D., Agusto, F., Aryati, L., Lenhart, S., Toaha, S., Widodo \& Govaerts, W. (2015). Stability analysis of rabies model with vaccination effect and culling in dogs. Applied Mathematical Sciences, 9(77), 3805-3817. doi: 10.12988/ams.2015.53197

[3] Beay, L. K., Kasbawati \& Toaha, S. (2017). Effects of human and mosquito migrations on the dynamical behavior of the spread of malaria AIP Conference Proceedings 1825, 020006. doi:10.1063/1.4978975

[4] Hartati, H., Toaha, S. \& Kasbawati (2019). Stability analysis of SEISEIR-SEI modelling on the dynamics of spread dengue fever with vaccination and insecticide. $J$. Phys.: Conf. Ser. 1341 062033. doi:10.1088/1742-6596/1341/6/062033

[5] Muin, R. M., Toaha, S. \& Kasbawati (2019). Effect of vaccination and treatment on the MSEICR model of the transmission of hepatitis B virus. J. Phys.: Conf. Ser. 1341 062031. doi:10.1088/1742-6596/1341/6/062031

[6] Asamoah, J. K., Nyabadza, F., Seidu, B., Chand, M., \& Dutta , H. (2018). Mathematical modelling of bacterial meningitis transmission dynamics with control measures. Computational and Mathematical Methods in Medicine, 1-21. doi: $10.1155 / 2018 / 2657461$

[7] Agier, L., Martiny, N., Thiongane, O., Mueller, J. E., Paireau, J., Watkins, E. R., . . Broutin, H. (2017). Towards understanding the epidemiology of Neisseria meningitidis in the African meningitis belt: a multi-disciplinary overview. International Journal of Infectious Diseases, 54, 103-112. doi: 10.1016/j.ijid.2016.10.032

[8] Martcheva, M., \& Crispino-O'Connell, G. (2003). The Transmission of meningococcal infection: a mathematical study. Journal of Mathematical Analysis and Applications, 283, 251-275. doi:10.1016/s0022-247x(03)00289-0

[9] Martínez, M. F., Merino, E. G., Sanchez, E. G., Sanchez, J. G., Rey, A. D., \& Sanchez, G. R. (2013). A mathematical model to study the meningococcal meningitis. International Conference on Computational Science, 18, 2492-2495. doi:10.1016/j.procs.2013.05.426 
Sulma, Syamsuddin Toaha, Kasbawati

[10] Brauer, F., \& Castillo-Chavez, C. (2012). Mathematical Models in Population Biology and Epidemiology (Second Edition ed.). New York: Springer Science+Business Media.

[11] Broutin, H., Philippon, S., Magny, G. C., Courel, M.-F., Sultan, B., \& Guegan, J.-F. (2007). Comparative study of meningitis dynamics across nine African countries: a global perspective. International Journal of Health Geographics, 1-8. doi:10.1186/1476-072x-6-29

[12] Blyuss, K. B. (2016). Mathematical modelling of the dynamics of meningococcal meningitis in Afrika. UK Success Stories in Industrial Mathematics, 221-226. doi:10.1007/978-3-319-25454-8_28

[13] Toaha, S. (2013). Pemodelan Matematika dalam Dinamika Populasi. Makassar: Dua Satu Press. 